\title{
The FRAIL-NH Scale: Systematic Review of the Use, Validity and Adaptations for Frailty Screening in Nursing Homes
}

\author{
S.J. Liau ${ }^{1,2}$, S. Lalic ${ }^{1,3}$, R. Visvanathan ${ }^{2,4}$, L.A. Dowd ${ }^{1}$, J.S. Bell ${ }^{1,2}$

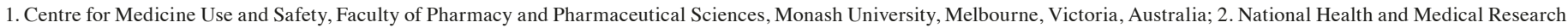

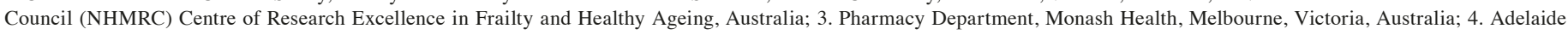

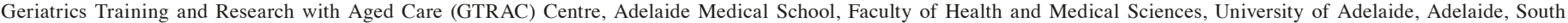 \\ Australia, Australia.
}

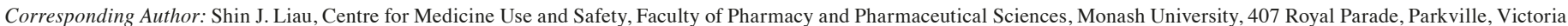
3052, Australia.E-mail: shin.liau@monash.edu

\begin{abstract}
OBJECTIVES: To investigate frailty prevalence, cross-sectional associations, predictive validity, concurrent validity, and cross-cultural adaptations of the FRAIL-NH scale.

DESIGN: Systematic review.

SETTING AND PARTICIPANTS: Frail residents living in nursing homes.

METHODS: MEDLINE, EMBASE, CINAHL, and Cochrane Library were searched from January 2015 to June 2021 for primary studies that used the FRAIL-NH scale, irrespective of study designs and publication language.

RESULTS: Overall, 40 studies conducted across 20 countries utilized the FRAIL-NH scale; majority in Australia $(n=14)$, followed by China $(n=6)$, United States $(n=3)$, and Spain $(n=3)$. The scale has been translated and back-translated into Brazilian Portuguese, Chinese, and Japanese. Various cut-offs have been used, with $\geq 2$ and $\geq 6$ being the most common cut-offs for frail and most frail, respectively. When defined using these cut-offs, frailty prevalence varied from 15.1-79.5\% (frail) to $28.5-75.0 \%$ (most frail). FRAIL-NH predicted falls $(\mathrm{n}=2)$, hospitalization or length of stay $(n=4)$, functional or cognitive decline $(n=4)$, and mortality $(n=9)$ over a median follow-up of 12 months. FRAIL-NH has been compared to 16 other scales, and was correlated with Fried's phenotype (FP), Frailty Index (FI), and FI-Lab. Four studies reported fair-to-moderate agreements between FRAIL-NH and FI, FP, and the Comprehensive Geriatric Assessment. Ten studies assessed the sensitivity and specificity of different FRAIL-NH cutoffs, with $\geq 8$ having the highest sensitivity $(94.1 \%)$ and specificity $(82.8 \%)$ for classifying residents as frail based on FI, while two studies reported an optimal cut-off of $\geq 2$ based on FI and FP, respectively.

CONCLUSION: In seven years, the FRAIL-NH scale has been applied in 20 countries and adapted into three languages. Despite being applied with a range of cut-offs, FRAIL-NH was associated with higher care needs and demonstrated good agreement with other well-established but more complex scales. FRAIL-NH was predictive of adverse outcomes across different settings, highlighting its value in guiding care for frail residents in nursing homes.
\end{abstract}

Key words: FRAIL-NH, frailty, frail older adults, nursing homes, residential facilities.

Received September 7, 2021

Accepted for publication September 22, 2021

\section{Introduction}

- railty is a potentially reversible state of health $\checkmark$ characterized by decreased physiological reserve and increased vulnerability to adverse outcomes including falls, hospitalization and mortality (1-6). The pooled prevalence estimates of frailty are $10.7 \%$ in community settings (7), and $52.3 \%$ in nursing home (NH) settings (8). The International Association of Gerontology and Geriatrics has advocated for increased research in NHs (9). Timely identification of residents who are frail or at risk of frailty may assist with early implementation of interventions to prevent adverse outcomes, as well as improve care planning and resource use. There is emerging evidence that residents who are frail are more susceptible to adverse drug events (ADEs) and therefore have a different benefit-to-risk ratio for long-term preventative medications (10-12). Additionally, assessing residents' frailty status may facilitate timely advance care planning and provision of palliative services to avoid unnecessary hospitalization and exposure to futile interventions at the end of life (13).

Currently, there is no international gold standard for screening or diagnosing frailty in NHs. Despite the plethora of frailty tools available, most have been developed for use in community or clinical settings (14). Fried's phenotype (FP) (15) and the Frailty Index (FI) (16) remain among the most commonly used diagnostic measures but are challenging to administer in NHs. The FRAIL-NH scale is a 7-item screening tool specifically designed for NHs (17). It includes domains related to potentially reversible variables including: fatigue; resistance; ambulation; incontinence or illness; loss of weight; nutritional approach; and help with dressing (17). Each item is assigned a score of up to 2 points, generating a total score of 0 (non-frail) to 14 (most frail) (17). The FRAIL-NH scale is gaining popularity but no reviews have critically evaluated the literature on the use of the scale. The aim of this systematic review was to investigate the use, validity and adaptations of the FRAIL-NH scale. 
Table 1. Characteristics of Included Studies

\begin{tabular}{|c|c|c|c|c|c|c|c|}
\hline Author, Year & Country & Study Description & $\begin{array}{l}\text { Year(s) of Data } \\
\text { Collection }\end{array}$ & Setting & $\begin{array}{l}\text { Study } \\
\text { Sample }\end{array}$ & Mean Age \pm SD & Female, \% \\
\hline $\begin{array}{l}\text { Archibald, } 2020(21 \text {, } \\
34)\end{array}$ & Australia & Interpretive descriptive qualitative study & 2017 & $2 \mathrm{NHs}$ & $17^{*}$ & - & - \\
\hline Buckinx, 2018 (53) & Belgium & Baseline and 1-year follow-up analysis of SENIOR study & 2013 & $28 \mathrm{NHs}$ & 662 & $83.2 \pm 9.0$ & 73 \\
\hline $\begin{array}{l}\text { Chen, } 2019(22) ; \\
\text { Dugré, } 2021(32) ; \\
\text { Sharma, } 2021(33) ; \\
\text { Sluggett, } 2020(27,28)\end{array}$ & Australia & $\begin{array}{l}\text { Cross-sectional analyses of baseline and 12-month } \\
\text { follow-up data from SIMPLER RCT }\end{array}$ & 2017 & $8 \mathrm{NHs}$ & 242 & 86 & 74 \\
\hline Chong, 2021 (52) & Singapore & Secondary analysis of a prospective cohort study & 2015 & $1 \mathrm{HD}$ & 210 & $89.4 \pm 4.6$ & 70 \\
\hline Chu, 2021 (54) & Canada & $\begin{array}{l}\text { Cross-sectional analysis of baseline data from a } \\
\text { development study }\end{array}$ & 2018-2019 & $2 \mathrm{NHs}$ & $13 \dagger$ & 83.23 & 62 \\
\hline $\begin{array}{l}\text { Contreras Escámez, } \\
2020(41) \ddagger\end{array}$ & Spain & Longitudinal cohort study & 2015-2018 & $2 \mathrm{NHs}$ & 110 & $86.3 \pm 7.3$ & 72 \\
\hline de Barros, 2021 (48) & Brazil & Cross-sectional seroepidemiological study & 2020 & $15 \mathrm{NHs}$ & 209 & Median 81 & 65 \\
\hline De Silva, 2018 (56) & France & Baseline and 1-year follow-up analysis of INCUR study & 2012 & $13 \mathrm{NHs}$ & 788 & $86.2 \pm 7.5$ & 75 \\
\hline $\mathrm{Ga}, 2018(59)$ & South Korea & Retrospective review of medical records & 2011-2017 & $1 \mathrm{LTCH}$ & 100 & $\begin{array}{l}\text { Male } 76.5 \pm 8.0 \\
\text { Female } 81.5 \pm 7.2\end{array}$ & 47 \\
\hline $\mathrm{Ge}, 2019(35-37) \S$ & China & Cross-sectional study & 2018 & $6 \mathrm{NHs}$ & 302 & $82.7 \pm 8.5$ & 71 \\
\hline Greco, 2021 (58) & Italy & Nested case-control study & 2019-2020 & $2 \mathrm{NHs}$ & 152 & $85.3 \pm 7.3$ & 74 \\
\hline $\begin{array}{l}\text { Gutiérrez-Valencia, } \\
2018 \text { (42); } \\
\text { Martínez-Velilla, } 2017 \\
\text { (43) }\end{array}$ & Spain & $\begin{array}{l}\text { Cross-sectional analyses of baseline data from a } \\
\text { longitudinal cohort study }\end{array}$ & 2015 & $2 \mathrm{NHs}$ & 110 & $86.3 \pm 7.3$ & 72 \\
\hline $\begin{array}{l}\text { Hendrix, } 2019 \text { (23); } \\
\text { Theou, } 2016(29) \text {; } \\
\text { Wang, } 2021 \text { (31) }\end{array}$ & Australia & $\begin{array}{l}\text { Cross-sectional analyses of baseline data from a } \\
\text { prospective cohort study }\end{array}$ & 2014 & $6 \mathrm{NHs}$ & 383 & $87.5 \pm 6.2$ & 78 \\
\hline Ho, 2020 (51) & Singapore & Retrospective review of case records & 2015 & $1 \mathrm{HD}$ & 189 & $84.3 \pm 8.6$ & 57 \\
\hline Jadczak, 2021 (24) & Australia & $\begin{array}{l}\text { Cross-sectional analysis of baseline data from FIRST } \\
\text { study }\end{array}$ & 2019-2020 & $12 \mathrm{NHs}$ & 561 & $87.7 \pm 7.3$ & 73 \\
\hline Kaehr, 2016 (44) & US & Retrospective study using MDS \& chart review & 2014 & $2 \mathrm{NHs}$ & 270 & - & 76 \\
\hline Kerry, 2020 (25) & Australia & Secondary analysis of a prospective cohort study & 2014 & $6 \mathrm{NHs}$ & 239 & $88.1 \pm 6.3$ & 79 \\
\hline $\begin{array}{l}\text { Korhonen, } 2018(26) \text {; } \\
\text { Theou, } 2018(30)\end{array}$ & Australia & Prospective cohort study & 2014 & $6 \mathrm{NHs}$ & 383 & $87.5 \pm 6.2$ & 78 \\
\hline Little, 2021 (46) & US & Descriptive observational study & 2016-2017 & $2 \mathrm{NHs}$ & 247 & - & 72 \\
\hline Luo, 2015 (57) & Hong Kong & Longitudinal follow-up study & $2005-2013$ & $6 \mathrm{NHs}$ & 2380 & $82.8 \pm 8.1$ & 68 \\
\hline $\begin{array}{l}\text { Papadopoulos, } 2021 \\
(50)\end{array}$ & $\begin{array}{l}\text { England \& } \\
\text { Japan }\end{array}$ & $\begin{array}{l}\text { Baseline cross-sectional screening for resident eligibility } \\
\text { in CARESSES RCT }\end{array}$ & 2019 & $9 \mathrm{NHs}$ & 33 & $81.9 \pm 9.8$ & 67 \\
\hline Peng, $2020(60)$ & Taiwan & Cross-sectional study & - & $1 \mathrm{NH}$ & 34 & $83.9 \pm 10.8$ & 53 \\
\hline Sakata, 2021 (49)\| & Japan & Methodological study & - & - & - & - & - \\
\hline $\mathrm{Si}, 2020(38)$ & China & Cross-sectional study & 2015-2016 & $23 \mathrm{NHs}$ & 305 & $79.3 \pm 8.4$ & 57 \\
\hline $\begin{array}{l}\text { Vasconcellos Romani- } \\
\text { ni, } 2020 \text { (47) }\end{array}$ & Brazil & Longitudinal cohort study & 2018 & $6 \mathrm{NHs}$ & 293 & $80.3 \pm 8.8$ & 65 \\
\hline Villani, 2021 (55) & $\begin{array}{l}\text { Europe \& } \\
\text { Israel }\end{array}$ & $\begin{array}{l}\text { Cross-sectional analysis of baseline data from SHELTER } \\
\text { study }\end{array}$ & 2009-2011 & $57 \mathrm{NHs}$ & 4121 & $84.6 \pm 9.2$ & 76 \\
\hline Yang, 2018 (39) & China & Prospective study & 2016-2017 & $4 \mathrm{NHs}$ & 329 & $85.2 \pm 3.4$ & 68 \\
\hline Yuan, 2021 (45) & US & Retrospective longitudinal study & 2014-2016 & $\begin{array}{l}15,551 \\
\text { NHs }\end{array}$ & 571,139 & $82.5 \pm 8.5$ & 67 \\
\hline Zhao, 2020 (40) & China & Methodological and cross-sectional study & 2018 & $27 \mathrm{NHs}$ & 353 & $79.0 \pm 8.8$ & 56 \\
\hline
\end{tabular}

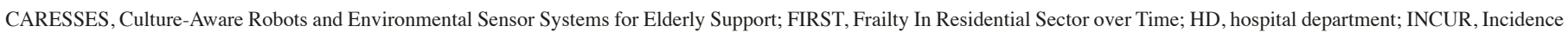

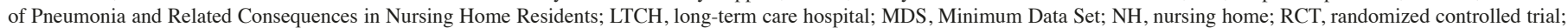

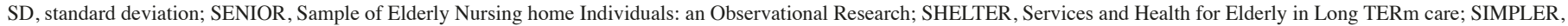

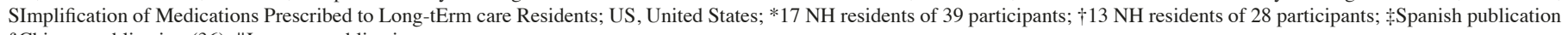
§Chinese publication (36); IIJapanese publication 


\section{Methods}

The systematic review was conducted in accordance with the Preferred Reporting Items for Systematic Reviews and MetaAnalyses (PRISMA) statement (18). The review protocol was published on PROSPERO (CRD42020185159) (19).

\section{Search Strategy}

MEDLINE, EMBASE, CINAHL, and Cochrane Library were searched from January 2015, when the FRAIL-NH scale was first published, to June 2021 (Supplement 1). For the purpose of this review, the term $\mathrm{NH}$ was considered synonymous with long-term care facilities and residential aged care services. Where relevant conference abstracts were identified, an author and title search were conducted to locate potential full-text articles. Reference lists of included articles were screened for additional relevant studies. A keyword search was conducted on PubMed and Google Scholar to identify additional studies.

\section{Study Selection}

Title and abstract screening were performed by two independent investigators (SJL, LAD), followed by a fulltext review. Primary studies using the FRAIL-NH scale were eligible for inclusion. Although FRAIL-NH was developed for use in NHs, studies using FRAIL-NH in other settings including hospitals were not excluded. Non-primary studies (e.g. literature reviews) and studies that did not use the FRAIL$\mathrm{NH}$ scale were excluded. There were no restrictions on study designs and publication language. For non-English studies, the original authors and/or bilingual researchers were contacted to extract data in English.

\section{Data Extraction}

Data extraction was performed independently by the same two investigators using a standardized table. Data extracted included study design, country, setting, and resident characteristics. The following FRAIL-NH data were extracted: cut-off points, prevalence, cross-sectional associations, predictive validity, concurrent validity, and adaptations. All study outcomes and variables that assessed for a relationship with FRAIL-NH were recorded. Cross-sectional associations examined the relationship between frailty and other variables of interest in the population. Predictive validity was defined as the ability of FRAIL-NH scores to predict health outcomes. Concurrent validity assessed the performance of FRAIL-NH in comparison to other scales. Cross-cultural adaptations were defined as translations and validations of FRAIL-NH for use in different linguistic, cultural and geographical regions. Authors were contacted in the event of missing data.

\section{Quality Assessment}

Quality assessment was conducted independently by the same two investigators using adapted versions of the Joanna Briggs Institute checklists for analytical cross-sectional studies and cohort studies (Tables S1 to S4) (20). The checklists were used to appraise the quality of how frailty was assessed using the FRAIL-NH scale (i.e. not the overall quality of study), irrespective of whether frailty was the primary focus of these studies. FRAIL-NH was deemed to be measured in a valid and reliable way where clear descriptions of FRAIL-NH application, or how FRAIL-NH was computed from other valid datasets were provided. Quality assessment was not applicable to studies that did not investigate cross-sectional associations or longitudinal outcomes according to frailty status. Any disagreements were resolved by discussion with additional investigators (JSB, SL).

\section{Results}

A total of 1,350 studies were retrieved, of which, 40 studies applied the FRAIL-NH scale (Figure 1). Studies were published in English $(n=37)$, Chinese $(n=1)$, Japanese $(n=1)$, and Spanish $(\mathrm{n}=1)$ (Table 1).

\section{Figure 1. PRISMA flow diagram of literature search and study selection}

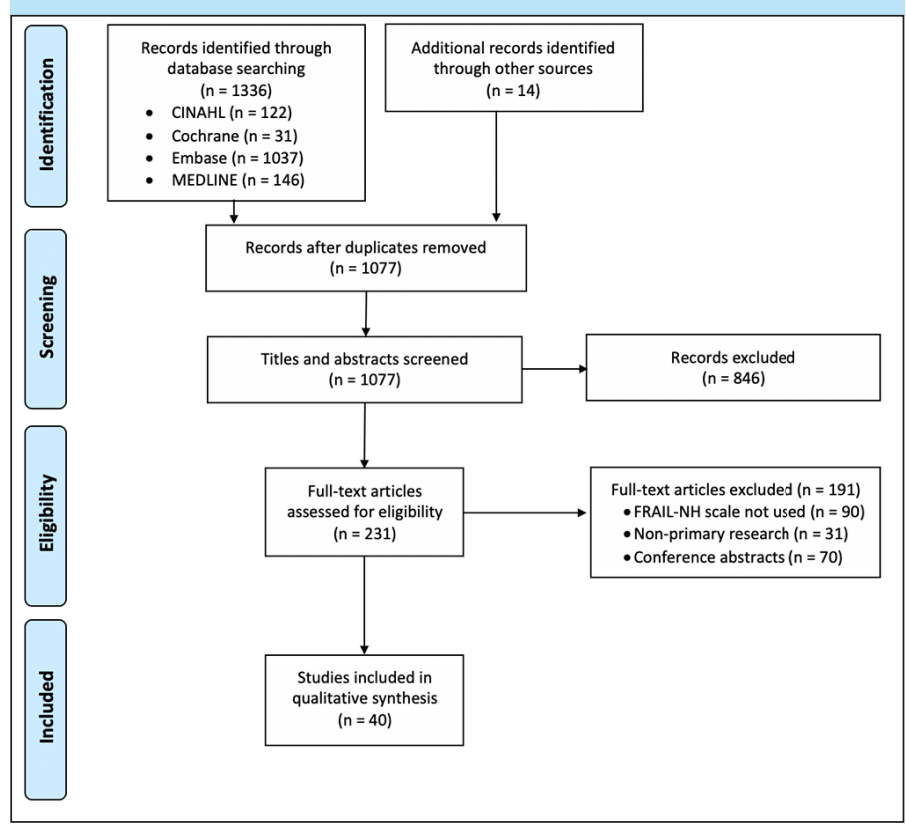

\section{Study and Resident Characteristics}

The FRAIL-NH scale was applied in studies across 20 countries; the majority in Australia $(n=14)(21-34)$, followed by China $(n=6)(35-40)$, Spain $(n=3)(41-43)$, United States (US) $(n=3)(44-46)$, Brazil $(n=2)(47,48)$, Japan $(n=2)(49,50)$, Singapore $(n=2)(51,52)$, Belgium $(n=1)(53)$, Canada $(n=1)$ (54), England $(n=1)(50)$, Europe and Israel $(n=1)(55)$, France $(n=1)(56)$, Hong Kong $(n=1)(57)$, Italy $(n=1)(58)$, South 
Table 2. Characteristics of FRAIL-NH, Frailty Prevalence, and Cross-Sectional Associations with Frailty

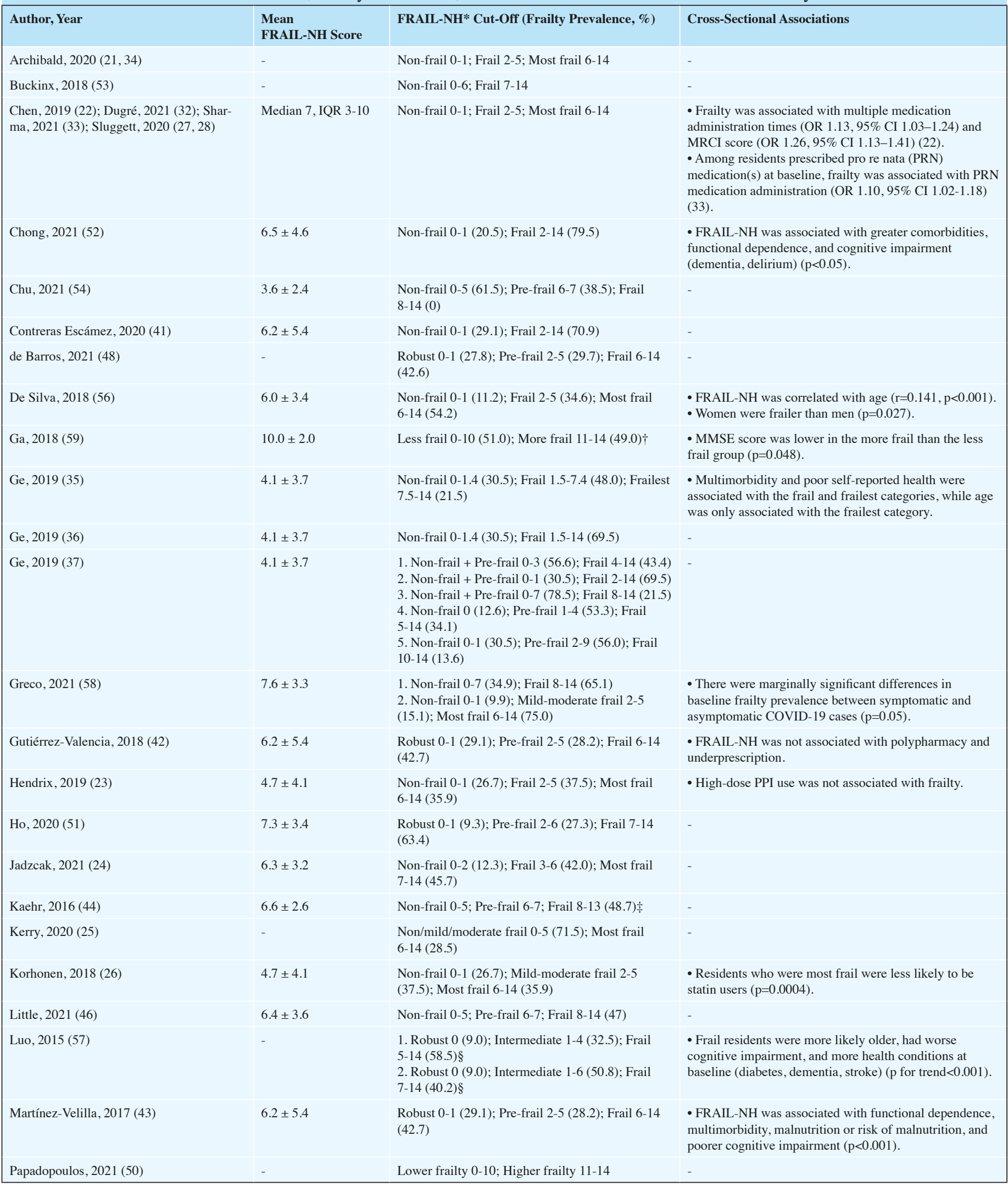


Table 2 (continued). Characteristics of FRAIL-NH, Frailty Prevalence, and Cross-Sectional Associations with Frailty

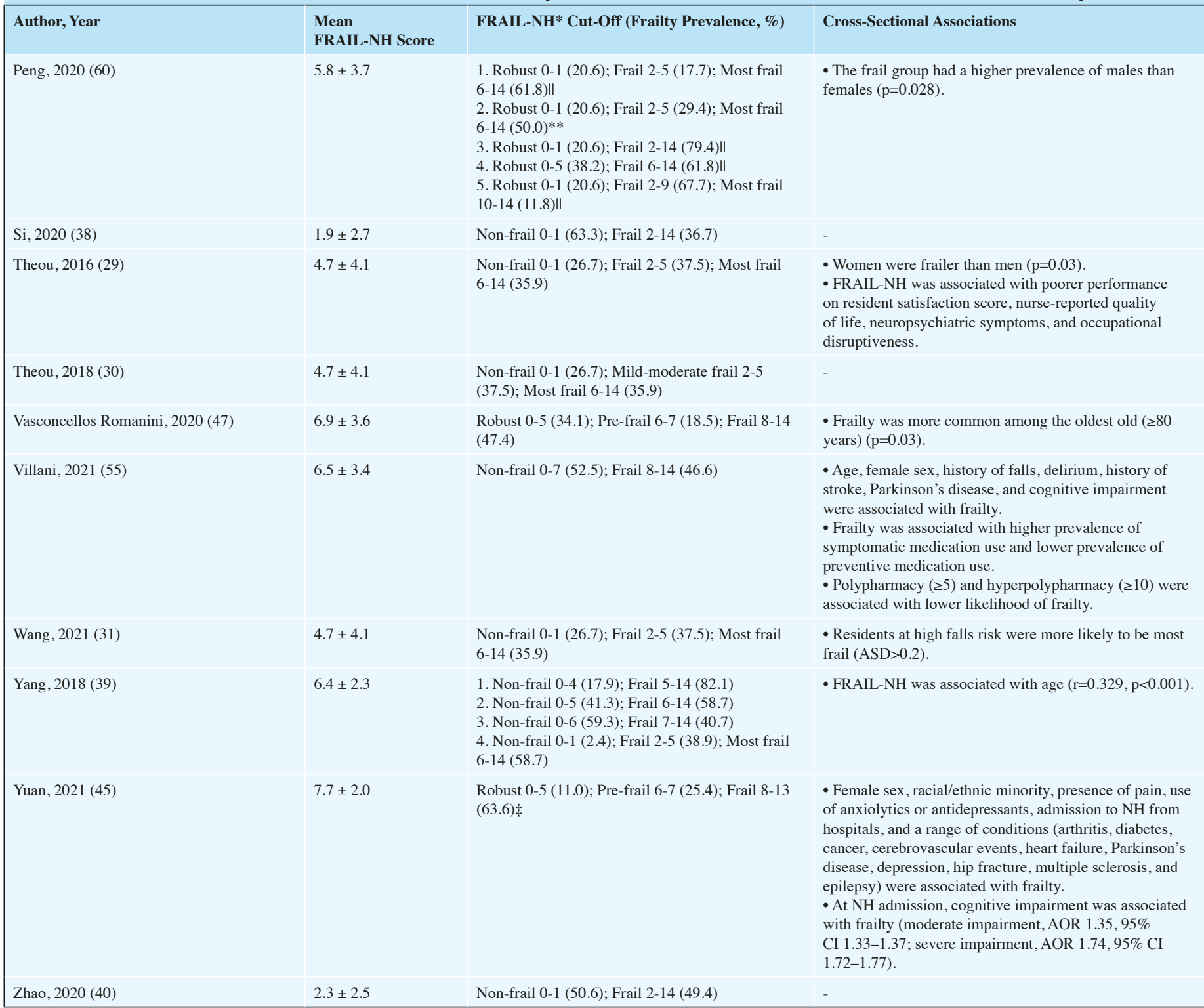

AOR, adjusted odds ratio; ASD, absolute standardized difference; CI, confidence interval; IQR, Interquartile range; MRCI, Medication Regimen Complexity Index; MMSE, Mini-Mental State Examination; NH, nursing home; OR, odds ratio; *FRAIL-NH range: 0-14; †6-item FRAIL-NH: excluded F=Fatigue domain; $\$$ FRAIL-NH range: 0-13 only; 88 -item FRAIL-NH: used both I=Incontinence and Illness domains; II7-item FRAIL-NH: used I=Incontinence domain; **7-item FRAIL-NH: used I=Illness domain

Korea $(n=1)(59)$, and Taiwan $(n=1)(60)$. One study was an international multicenter study based on data from the Services and Health for Elderly in Long TERm care (SHELTER) study, conducted in 8 countries including Czech Republic, England, Finland, France, Germany, Israel, Italy, and the Netherlands (55).

Study designs included observational studies $(n=31)$, experimental studies $(n=6)$, qualitative studies $(n=2)$, and a methodological study $(n=1)$ (Table 1$)$. Six articles utilized data from an Australian cohort study (23, 25, 26, 29-31), five from an Australian randomized controlled trial (RCT) $(22,27,28,32$, 33 ), three from a Spanish longitudinal study (41-43), and three from a Chinese cross-sectional study (35-37). The number of participants ranged from 13 to 571,139 , with a mean age range of $79.0 \pm 8.8$ to $89.4 \pm 4.6$ years. Of the 40 studies, 36 studies were conducted in NHs, three studies in hospital settings, and one study reported the scale translation (Table 1).

\section{Frailty Prevalence}

Frailty prevalence was reported in 30 of 40 studies, with FRAIL-NH cut-offs ranging from 1.5 to 11 (Table 2). The most frequent cut-off for defining frail and most frail residents were $\geq 2(\mathrm{n}=21)(21-23,26-34,37-41,52,56,58,60)$ and $\geq 6(\mathrm{n}=13)$ $(21,22,25,26,29,30,32-34,39,56,58,60)$, respectively. When applying these definitions, between $15.1 \%$ and $79.5 \%$ of residents were frail, while $28.5 \%$ to $75.0 \%$ of residents were most frail. Other common cut-offs used to define frailty were $\geq 6(n=5)(39,42,43,48,60)$ and $\geq 8(n=8)(37,44-47$, $54,55,58)$. Ten studies assessed the sensitivity and specificity 
Table 3. Predictive validity of the FRAIL-NH scale

\begin{tabular}{|c|c|}
\hline Author, Year & Predictive validity of FRAIL-NH \\
\hline Buckinx, 2018 (53) & - Not predictive of falls and mortality at 1 year. \\
\hline Chong, 2021 (52) & $\begin{array}{l}\text { - Predictive of mortality at } 6 \text { months (OR 13.6,95\% CI 1.80-103.12) and } 12 \text { months (OR 6.62,95\% CI 1.91-22.94). } \\
\text { - Predictive of NH admission at } 6 \text { months (OR 4.98, 95\% CI 1.45-17.13) and } 12 \text { months (OR 6.03, 95\% CI 2.01-18.09). } \\
\text { - Associated with functional decline at } 6 \text { months (OR 2.57,95\% CI 1.23-5.35) and } 12 \text { months (OR 2.22, 95\% CI 1.07-4.62). }\end{array}$ \\
\hline Contreras Escámez, 2020 (41) & $\begin{array}{l}\text { - Predictive of functional and cognitive decline at } 3 \text { years }(\mathrm{p}<0.001) \text {, but not predictive of mortality. } \\
\text { - Frail residents more often died at their } \mathrm{NHs}(\mathrm{p}=0.004) \text { and had shorter hospitalization }(\mathrm{p}=0.005) \text { compared to robust residents. }\end{array}$ \\
\hline De Silva, 2018 (56) & - Predictive of mortality at 1 year (adjusted HR for frail $1.15,95 \%$ CI $0.55-2.41$; most frail $2.14,95 \%$ CI $1.07-4.27$ ). \\
\hline $\mathrm{Ga}, 2018(59)$ & $\begin{array}{l}\text { - Associated with earlier mortality in more frail patients admitted to a long-term care hospital (HR } 1.29,95 \% \text { CI } 1.29-2.98) \text {. } \\
\text { - Within the last } 6 \text { months of hospital stay, tube feeding was more common in the more frail group than in the less frail group ( } \mathrm{p}=0.034) \text {. } \\
\text { - Mean survival duration was shorter in the more frail group than in the less frail group ( } \mathrm{p}=0.002 \text { ). }\end{array}$ \\
\hline Greco, $2021(58)$ & - Frailty was associated with cognitive decline from pre- to post-COVID assessment (OR 2.76, 95\% CI 1.07-7.12). \\
\hline Ho, $2020(51)$ & $\begin{array}{l}\text { - Despite similar frailty status, young-old (65-79 years) patients had higher healthcare utilization than old-old patients ( } \geq 80 \text { years). } \\
\text { - Not predictive of recurrent hospital admissions in the terminal phase. }\end{array}$ \\
\hline Kaehr, 2016 (44) & $\begin{array}{l}\text { - Pre-frail residents were associated with an increased 6-month risk of falls ( } \mathrm{AOR}=2.63,95 \% \mathrm{CI}=1.25-5.54) \text {. } \\
\text { - Frail residents were associated with 6-month mortality or hospice enrolment (AOR=3.96, 95\% CI=1.44-10.87). } \\
\text { - Combining pre-frail and frail categories, FRAIL-NH predicted 6-month mortality or hospice enrolment (AOR=3.36; 95\% CI=1.26-8.98). } \\
\text { - FRAIL-NH was not predictive of hospitalization. }\end{array}$ \\
\hline Kerry, $2020(25)$ & $\begin{array}{l}\text { - Among residents who were most frail, multiple antihypertensive use was associated with an increased risk of mortality (HR } 2.52,95 \% \text { CI } \\
1.13-5.64) \text {. }\end{array}$ \\
\hline Korhonen, 2018 (26) & $\begin{array}{l}\text { - Among statin users, the risk of fall-related hospitalizations was greater among mild-moderate and most frail residents. } \\
\text { - Among non-users of statin, most frail residents were nearly } 70 \% \text { less likely to experience a fall-related hospitalization compared to } \\
\text { robust residents. }\end{array}$ \\
\hline Luo, 2015 (57) & 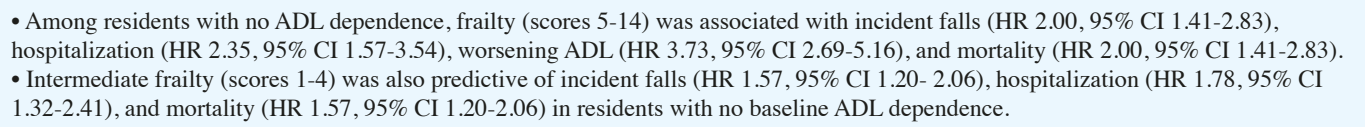 \\
\hline Theou, 2018 (30) & $\begin{array}{l}\text { - Mild-moderately frail residents had higher numbers of hospitalizations (adjusted IRR } 1.57,95 \% \text { CI } 1.11-2.20 \text { ) and hospital days (IRR } \\
1.48,95 \% \text { CI } 1.32-1.66 \text { ) than non-frail residents. } \\
\text { - Most frail residents were at higher risk of mortality (adjusted HR } 2.96,95 \% \text { CI } 1.50-5.83 \text { ), but had lower numbers of hospitalizations } \\
\text { (IRR } 0.65,95 \% \text { CI } 0.42-0.99 \text { ) and hospital days (IRR } 0.39,95 \% \text { CI } 0.33-0.46 \text { ) than non-frail residents. } \\
\text { - Over } 12 \text { months, more than } 20 \% \text { of most frail residents but less than } 3 \% \text { of non-frail residents died at the NH without hospitalization. }\end{array}$ \\
\hline Vasconcellos Romanini, 2020 (47) & - Predictive of mortality at 12 months $(\mathrm{OR}=1.31,95 \% \mathrm{CI}=1.18-1.48)$. \\
\hline Yang, $2018(39)$ & $\begin{array}{l}- \text { Frailty defined by FRAIL-NH } \geq 6 \text { (adjusted HR } 2.00,95 \% \text { CI 1.18-3.42) or } \geq 7 \text { (adjusted HR 2.31, 95\% CI 1.41-3.76) was associated with } \\
\text { 1-year mortality. } \\
\text { - Each one-score increment of FRAIL-NH was associated with an increased risk of mortality (adjusted HR 1.32, 95\% CI 1.19-1.46). }\end{array}$ \\
\hline
\end{tabular}

ADL, activities of daily living; CI, confidence interval; COVID-19, coronavirus disease 2019; HR, hazard ratio; IRR, incidence rate ratio; OR, odds ratio.

of different cut-offs $(24,29,35-40,47,52)$, with $\geq 8$ having the highest sensitivity $(94.1 \%)$ and specificity $(82.8 \%)$ for classifying residents as frail based on FI (37), while two studies reported an optimal cut-off of $\geq 2$ using FI and FP, respectively $(29,40)$. Optimal cut-offs were primarily established based on FI, FP, or the Comprehensive Geriatric Assessment (CGA), and determined using Youden Index or receiver operating characteristic curves. Ten studies described how FRAIL-NH scores were computed from a combination of other validated scales and datasets (Table S5). All but two studies used the original score range of $0-14$ and the complete seven domains $(57,59)$.

\section{Cross-Sectional Associations}

Cross-sectional associations were described in 18 studies (Table 2). Fifteen studies reported univariate or bivariate associations $(23,26,29,31,33,39,43,45,47,52,56-60)$; while four studies adjusted analyses for age, sex, and other variables $(22,35,42,55)$. FRAIL-NH scores were associated with older age $(35,39,47,55-57)$, female sex $(29,45,55-57)$, multimorbidity $(35,43,52,57)$, cognitive impairment $(43,45$,
$52,55,57,59)$, and functional dependence $(43,52)$.

A longitudinal study of 571,139 residents in 15,551 US NHs found an association between frailty and diabetes, cancer, stroke, heart failure, Parkinson's disease, and depression (45). Residents experiencing pain, and those receiving anxiolytics or antidepressants at admission were more likely frail (45). Conversely, residents receiving hypnotics and antipsychotics were less likely frail (45). A cohort study of 383 residents in six Australian NHs found residents at high falls risk were more likely to be most frail compared with residents at low falls risk (31). Polypharmacy $(42,55)$, underprescription (42), preventive medication use $(26,55)$, and high-dose proton pump inhibitor use (23), were found to have no associations or were inversely associated with frailty.

\section{Predictive Validity}

Predictive validity was investigated in 14 studies (Table 3 ). FRAIL-NH scores were predictive of mortality $(25,30,39,44$, $47,52,56,57,59)$, falls $(44,57)$, hospitalization $(26,30,57)$, length of hospitalization $(30,41)$, and functional or cognitive decline $(41,52,57,58)$ over a median follow-up of 12 months. 


\section{Table 4. Concurrent validity of the FRAIL-NH scale}

\begin{tabular}{l|l}
\hline Author, Year & Comparison between FRAIL-NH and other frailty scales \\
\hline Buckinx, 2018 (53) & CFS, EFS, FRAIL, FI, FP, GFI, SEGA, SHARE-FI, SQ, TFI \\
\hline Chong, 2021 (52) & FRAIL, FI*
\end{tabular}

\section{Concurrent validity of FRAIL-NH}

Chong, 2021 (52) FRAIL, FI*

- None of the 11 scales were predictive of falls and deaths at 1 year.

- FRAIL-NH and FRAIL had good diagnostic performance (both AUC $>0.8, \mathrm{p}<0.001$ ) against FI, with FRAIL-NH identifying more patients as frail.

- FRAIL-NH had less ceiling effect than FRAIL in discrimination of severe frailty.

- FRAIL-NH was a better predictor of mortality (OR 6.62,95\% CI 1.91-22.94) and admission to NHs (OR 6.03, 95\% C 2.01-18.09).

- FRAIL was superior for predicting in-hospital mortality (OR 9.29,95\% CI 1.09-79.20) and length of stay ( $\mathrm{p}=0.043$ ).

Contreras Escámez, $\quad$ IF, FI, FP

$2020(41)$

- Only FP predicted falls $(\mathrm{p}<0.001)$

- Only IF demonstrated a relationship between frailty and mortality at 3 years (HR=3.3.95\% CI 1.5-7.1).

- Using FRAIL-NH and IF, frail residents were associated with shorter hospitalizations, functional and cognitive decline.

$\mathrm{Ga}, 2018$ (59)

FI

$\mathrm{Ge}, 2019$ (35)

FI

Ge, 2019 (36)

TFI, FI*

Ge, 2019 (37)

FI

Gutiérrez-Valencia, $\quad$ FP, IF, F

$2018(42)$

Jadczak, $2021(24) \quad$ FI

Kaehr, $2016(44) \quad$ Fl

Martínez-Velilla, $\quad$ IF, FI, FP

2017 (43)

$\mathrm{Si}, 2020(38)$

FP, FRAIL, GFI, TFI, CGA*

Theou, $2016(29)$

FI

Theou, $2018(30)$

FI

Yang, $2018(39) \quad$ FI-Lab

Zhao, 2020 (40) FI-35, SOF index, SPPB, FP
- Distribution of FRAIL-NH was in accordance with FI ( $\beta=0.571, p<0.001, r=0.572)$.

- Both scales showed a high prevalence of frailty in patients admitted to a long-term care hospital.

- Both scales were associated with earlier mortality (FRAIL-NH, HR 1.29, $95 \%$ CI 1.29-2.98; FI, HR 1.39, 95\% CI 1.101.76).

- FRAIL-NH and FI were strongly correlated $(\mathrm{r}=0.743, \mathrm{p}<0.001)$

- Agreement between both scales were modest $(x=0.392, \mathrm{p}<0.001)$, with FI classifying more residents as frail.

- Age was associated with an increased FI classification of frail or frailest, but was only associated with a FRAIL-NH classification of frailest.

- Both scales found that multimorbidity and poor self-reported health were associated with an increased risk of frail and frailest status.

- FRAIL-NH (AUC=0.861) had better diagnostic performance than TFI (AUC=0.776) $(\mathrm{Z}=3.455, \mathrm{p}<0.001)$

- FI tended to classify residents as frail, whereas FRAIL-NH tended to classify residents as pre-frail.

- Agreement between both scales ranged from fair to moderate $(x=0.33$ to 0.55$)$ regardless of the cut-offs used.

- No associations between frailty and polypharmacy based on all 4 scales.

- No associations between frailty and underprescription, except for FP where the limit of significance was reached.

- No significant differences in specific START criteria according to frailty status based on all 4 scales.

- FRAIL-NH was correlated with FI ( $\mathrm{r}=0.77, \mathrm{p}<0.001)$

- FRAIL-NH showed a positive correlation with FI ( $\mathrm{r}=0.623)$.

- FRAIL-NH was superior to FI at predicting falls in pre-frail residents ( $\mathrm{AOR}=2.42,95 \% \mathrm{CI} 1.11-5.92$ ), and mortality or hospice enrolment in frail residents (AOR=3.25, 95\% CI 1.04-10.86).

- Combining pre-frail and frail categories, both scales predicted 6-month mortality or hospice enrolment; however, FI was a more modest predictor (FRAIL-NH, $\mathrm{AOR}=3.36,95 \% \mathrm{CI}=1.26-8.98 ; \mathrm{FI}, \mathrm{AOR}=2.28 ; 95 \% \mathrm{CI}=1.01-5.15$ )

- Both scales were not predictive of hospitalization.

- Age was only associated with FP and FI ( $\mathrm{p}<0.05)$, but not IF or FRAIL-NH

- Based on all 4 scales, frail residents had more geriatric syndromes and a higher degree of cognitive impairment.

- Based on all 4 scales, no significant associations were found between frailty and depression or the level of education.

- Using IF, FI, and FRAIL-NH, frail residents had a higher percentage of malnutrition or risk of malnutrition.

- FRAIL-NH, FRAIL, FP, GFI, and TFI showed similarly good diagnostic accuracy in identifying frailty against CGA $(\chi 2=0.0003-1.38, p>0.05)$

- At the original cut-offs, all scales had: slight to moderate agreement with the CGA $(\chi=0.168-0.407)$; low sensitivity and high specificity; and high positive predictive values and low negative predictive values.

- At the optimal cut-offs of FRAIL-NH, FRAIL and FP: the agreement increased $(x=0.465-0.523)$; sensitivity and specificity were more balanced; and correctly classified rates increased.

- FRAIL-NH was associated with FI $(\mathrm{r}=0.81, \mathrm{p}<0.001)$

- FI was associated with age $(\mathrm{r}=0.11, \mathrm{p}=0.03)$, whereas FRAIL-NH was not.

-Women were frailer than men when assessed using both tools (FI, $\mathrm{p}=0.006, \mathrm{~d}=0.34$; FRAIL-NH, $\mathrm{p}=0.03, \mathrm{~d}=0.26$ )

- Both scales were associated $(\mathrm{p}<0.001)$ with health measures indicative of higher care needs (total resident satisfaction score, nurse-reported quality of life, neuropsychiatric symptoms, and occupational disruptiveness), with FI having stronger associations.

- In contrast to FRAIL-NH, FI was only associated with a higher number of hospital days, but not number of hospitalizations.

- Both scales found that most frail residents had a higher risk of mortality than non-frail residents (FRAIL-NH, adjusted HR 2.96, 95\% CI 1.50-5.83; FI, HR 5.28, 95\% CI 2.05-13.59).

- Among the lowest frailty subset in both scales, about a quarter of residents were hospitalized and were alive at 12 months; whereas among the most frail subset, a smaller proportion was hospitalized and alive at 12 months.

- Both scales found that among residents who died at the NH without hospitalization, this occurred to almost a quarter of the most frail subset, but only to a small number of the lowest frailty subset.

- FI-Lab was associated with FRAIL-NH ( $\mathrm{r}=0.799, \mathrm{p}<0.001)$.

- Both scales found that frailty was related to an increased risk of 1-year mortality (FRAIL-NH $\geq 6$, adjusted HR 2.00, 95\% CI 1.18-3.42; FI-Lab $\geq 0.3$, adjusted HR 2.26, 95\% CI 1.32-3.85).

- FI-Lab (AUC 0.700, 95\% CI 0.647-0.750) was slightly better than FRAIL-NH (AUC 0.676, 95\% CI 0.622-0.727) at predicting mortality.

- Each increment of score in both scales were associated with mortality (FRAIL-NH, adjusted HR per 1-score increment 1.32, 95\% CI 1.19-1.46; FI-Lab, adjusted HR per 0.01-score increment 1.07, 95\% CI 1.05-1.09).

- FRAIL-NH was associated with FP $(\mathrm{r}=0.61, \mathrm{p}<0.001)$, but only showed fair agreement $(x=0.46, \mathrm{p}<0.001)$ - FP identified more individuals with frailty than FRAIL-NH ( $<<0.001)$

- FRAIL-NH was moderately correlated to SOF index, FI-35, and SPPB.

AUC, area under curve; AOR, adjusted odds ratio; CFS, Clinical Frailty Scale; CGA, Comprehensive Geriatric Assessment; CI, confidence interval; EFS, Edmonton Frail Scale; FI, Frailty Index; FI-35, Frailty Index 35; FI-Lab, Frailty Index based on common laboratory tests; FP. Fried's phenotype; GFI, Groningen Frailty Indicator; HR, hazard ratio; IF, Imputed Fried; NH, nursing home; OR, odds ratio; SEGA, Short Emergency Geriatric Assessment; SHARE-FI, Survey of Health, Ageing and Retirement in Europe-Frailty Instrument; SOF, Study of Osteoporotic Fracture; SPPB, Short Physical Performance Battery; SQ, Strawbridge questionnaire; START, Screening Tool to Alert to Right Treatment; TFI, Tilburg Frailty Indicator; *Used as reference standard 
Among residents with no activities of daily living (ADL) dependence in a Hong Kong study $(n=2,380)$, FRAIL-NH predicted falls, worsening ADL, hospitalization, and mortality (57). A Chinese study $(n=329)$ reported that each one-score increment in FRAIL-NH increased the hazard ratio for 1-year mortality by $32 \%$ (39).

An Australian study $(n=383)$ reported that mild-moderately frail residents had higher numbers of hospitalizations and hospital days compared to non-frail residents, whereas most frail residents had lower numbers but were at higher risk of death (30). Over 12 months, more than $20 \%$ of most frail residents, but less than $3 \%$ of non-frail or vulnerable residents, died at the $\mathrm{NH}$ without hospitalization (30). Multiple antihypertensive use was associated with increased mortality among most frail residents in the same cohort (25). Statin use was associated with fall-related hospitalizations in mildmoderate and most frail residents (26). Conversely, among non-users of statins, fall-related hospitalizations were lowest in the frailest subset (26). Five studies reported contrasting outcomes whereby FRAIL-NH scores did not predict falls (53), hospitalization $(44,51)$, and mortality $(41,53)$.

\section{Concurrent Validity}

The FRAIL-NH scale has been compared to 16 other scales (Table 4). FRAIL-NH was correlated with FI (24, 29, 35, 44), FP (40), and FI-Lab (39). Four studies reported fair to moderate agreements between FRAIL-NH and FI $(35,37)$, FP (40), and CGA (38). A Chinese study $(n=305)$ reported that FRAIL-NH, FRAIL, FP, Groningen Frailty Indicator, and Tilburg Frailty Indicator demonstrated similarly good diagnostic properties against CGA (38). Of these scales, FRAIL-NH, FRAIL and FP had moderate agreements with CGA at the optimal cut-offs (38). In a Singaporean geriatric hospital $(n=210)$, FRAILNH and FRAIL had good diagnostic performance against FI (52). FRAIL-NH had less ceiling effect and had greater discriminatory ability for severe frailty than FRAIL (52).

Seven studies compared the predictive validity between FRAIL-NH and 12 other scales for mortality $(30,39,41,44$, $52,53,59)$, falls $(44,53)$, hospitalization $(30,44)$, length of hospitalization $(30,41,52)$, NH admission (52), functional and cognitive decline $(41,52)$. A US study $(n=270)$ reported that FRAIL-NH was superior to FI at predicting death in frail residents, and falls in pre-frail residents at 6-month follow-up (44). Conversely, FI-Lab was a better predictor of 1-year mortality than FRAIL-NH in a Chinese study $(n=329)$ (39). An Australian study $(n=383)$ found that residents with mild-moderate frailty based on FRAIL-NH and FI had longer hospitalization than non-frail residents (30). In contrast, a Spanish study $(n=110)$ reported that FRAIL-NH and Imputed Fried (IF) had similar predictive validity for shorter hospitalization, functional and cognitive decline (41). Although FRAIL was superior for in-hospital mortality and length of hospitalization in a Singaporean tertiary hospital study, FRAIL-NH better predicted mortality and NH admission up to 12-month follow-up (52).

\section{Cross-Cultural Adaptations}

At present, the FRAIL-NH scale has been translated into Brazilian Portuguese (47), Chinese (40), and Japanese (49). The scale was also applied to data from Italy (58), Korea (59), and Spain (41-43), although the translations and adaptations were not specifically reported. The Brazilian Portuguese version was generated through a process of translation by a geriatrician and a physical therapist, cross-cultural adaptation through consensus meetings, and back-translation by a native English speaker (47). The Chinese version was translated by two native bilingual speakers, back-translated by two US researchers, pilot trialed in a sample of $\mathrm{NH}$ residents $(n=38)$, and subsequently conducted a post-study interview to ascertain comprehensibility of the translated version (40). Similarly, the Japanese version was translated by two geriatricians and one pharmacist, backtranslated by a translation agency with designated expertise on geriatrics and gerontology, followed by a pilot $\mathrm{NH}$ trial, and a post-study evaluation (49).

\section{Other Applications}

The FRAIL-NH scale was used to investigate the impact of coronavirus disease 2019 (COVID-19) on changes in 152 Italian residents' frailty status over time (58). COVID-19 accelerated deterioration in frailty by $21 \%$, and COVID-19 survivors had a 4-fold higher chance of developing frailty (58). Frailty was associated with cognitive decline from pre- to post-COVID assessment $(58)$. A large US study $(n=571,139)$ reported that $23 \%$ of pre-frail residents at admission improved to robust by three months, whereas $30.5 \%$ of pre-frail residents transitioned to frail (45). At admission, residents with severe cognitive impairment were $74 \%$ more likely to be frail (45). By 6 months, those with severe impairment were over twice as likely to be frail (45). Other applications of FRAIL-NH include: establishing baseline comparability of participants in studies $(24,27,28,32,33,54)$; baseline screening as proxy to physical health for RCT recruitment (50); describing COVID19 seroprevalence in frail residents (48); characterizing frailty status in residents interviewed on perceptions of frailty (21, 34); examining changes in FRAIL-NH scores at annual routine screening (46); and the prospective use of FRAIL-NH in acute care $(52)$.

\section{Methodological Quality of Studies}

Of the 18 cross-sectional studies, 15 studies provided clear inclusion criteria (Table S3) (22-24, 29, 31, 33, 35-38, 40, $42,43,45,54)$. All studies described resident characteristics and settings in detail $(22-24,29,31,33,35-38,40,42,43$, $45,48,54,55,60)$. Cross-sectional associations with frailty were not investigated in seven studies $(24,36-38,40,48$, 54 ), therefore criteria related to confounding factors were not assessed in these studies. Residents with different frailty status were recruited from the same population, free of outcomes at the start of study, and follow-up time was reported in all 14 outcome studies (Table S4) $(25,26,30,39,41,44,47,51-53$, 
56-59). Confounding factors were identified and adjusted for in 13 outcome studies $(25,26,30,39,44,47,51-53,56-59)$. Overall, two studies did not provide adequate information on how FRAIL-NH was computed, which precluded assessment on whether the measurement was valid $(48,53)$.

\section{Discussion}

This was the first review of the use, validity and adaptations of the FRAIL-NH scale. FRAIL-NH has become widely used in Australia, Asia, Europe and North America. Frailty prevalence varied depending on the cut-off used. The optimal cut-off is dependent on the FRAIL-NH domains included, reference scale used, purpose of screening, setting, resident characteristics, structure and resources available. While a universal cut-off permits direct comparison across studies, it is not clear that optimal cut-offs are generalizable to all NHs. Although FI was commonly used as the reference for determining the optimal FRAIL-NH cut-off, FI scores were originally continuous instead of categorical, and the commonly applied FI cut-off of $\geq 0.22$ was based on studies analyzing different deficits in community instead of NH settings (61). The wide range in proportion of frail residents likely reflects differences in $\mathrm{NH}$ services in different countries. Lower cut-offs with higher sensitivity could improve frailty detection, whereas higher cut-offs with higher specificity could reduce misdiagnosis and enhance resource allocation $(38,52)$.

FRAIL-NH was associated with resident and clinical characteristics indicative of higher care needs. One study included in the review suggested frail residents had the most complex medication regimens (22). This is important because frail residents are susceptible to ADEs, and regimen complexity has been linked to medication errors and hospitalizations (62-65). Frailty may also be overlooked in residents with chronic multimorbidity in conventional disease-based treatment decision-making $(11,62,66)$. Use of a straightforward screening tool such as FRAIL-NH may assist in rapid identification of frailty to target clinical services (e.g. regimen simplification, medication reviews, CGA) to residents who may benefit most. Given that most $\mathrm{NH}$ residents have some degree of frailty, determining different levels of frailty (e.g. pre-frail, most frail) may allow assessment of residents most at risk of adverse outcomes for better care planning and resource allocation.

In addition, the FRAIL-NH scale may be useful for identifying residents at risk of various adverse outcomes such as hospitalization, functional decline, and ADEs. Among the five studies investigating all-cause hospitalization (26, 30, $44,51,57)$, three studies reported an association and two did not $(44,51)$, while another study reported FRAIL-NH scores further predicted fall-related hospitalization (26). Discrepancies in predictive validity may reflect different thresholds for hospitalization and differences in the extent to which clinical in-reach services are provided in NHs. Further studies on cause-specific hospitalizations are warranted to determine the reasons why frail residents are hospitalized and to develop preventive strategies. FRAIL-NH could guide development of individualized care plans to prevent falls, hospitalization and mortality. It is possible that the frailest residents may have advance care plans with do not hospitalize orders (30).

FRAIL-NH scores predicted functional decline in all three studies that examined this parameter $(41,52,57)$. Frail residents with no baseline ADL dependence were at increased risk of worsening ADLs in a 9-year longitudinal study (57). Functional independence is an important outcome measure that has been prioritized by residents and carers (62). Using FRAIL-NH to detect pre-frail residents may help direct interventions to prevent functional dependence. FRAIL-NH can be applied on a regular or as needed basis to ensure care goals are updated in alignment with shifts in frailty transition. Two studies demonstrated that frailty modified the risk-benefit ratio of preventive medications $(25,26)$. Statin users with mild-moderate frailty or who were most frail were at higher risk of fall-related hospitalization (26), whereas residents who were most frail and using multiple antihypertensives were at increased risk of mortality (25). FRAIL-NH could be used to identify residents at increased risk of ADEs and assist with tailoring medication regimens accordingly.

Overall, the FRAIL-NH scale demonstrated good agreement with other well-established but more complex frailty scales. FRAIL-NH had similar diagnostic and predictive properties as FI, FI-Lab, FP, IF, and FRAIL. Unlike FP, FRAIL-NH does not require use of specific instruments (e.g. dynamometer to measure handgrip strength) and measurement of gait speed which can be challenging in NHs. As many residents have functional dependence, assessing walking speed may be impractical. Although FI may be more comprehensive for care planning, it is resource intensive to manually code residents' deficits in the absence of electronic software. In contrast, FRAIL-NH is a simple and rapid scale that utilizes routinely collected data in NHs. The ease of administration makes FRAIL-NH a good candidate as a routine screening tool in NHs. Specialist training is not required to administer FRAIL$\mathrm{NH}$. This is supported by 24 studies reporting that care workers, technicians, or nurses effectively applied the scale (21-37, 39, 41-43, 49, 56, 59). Furthermore, FRAIL-NH can often be retrospectively applied to existing datasets as demonstrated by nine studies in this review $(44,45,51-53,55-57,59)$. This is feasible because most items in FRAIL-NH can be adapted from other validated scales that are routinely applied in NHs (Table S5).

\section{Strengths, Limitations and Implications for Future Research}

A key strength is the inclusion of all full-text primary studies from 20 countries that have used the FRAIL-NH scale from inception to present irrespective of study designs and publication language. The review provides a snapshot of the use of FRAIL-NH globally, excluding results from a Japanese abstract reporting that FRAIL-NH predicted $\mathrm{NH}$ admissions (67), and a Mexican abstract using the Spanish version of FRAIL-NH (68). To our knowledge, full-text articles for these abstracts have not been published. Extensive variability in 
study samples and FRAIL-NH cut-offs limited comparability of included studies. Findings from individual studies are not necessarily representative or generalizable to all frail $\mathrm{NH}$ residents in the corresponding countries. Cross-sectional study designs limit the prospect of exploring causal relationships. A meta-analysis was not performed due to heterogeneity in study objectives and outcomes investigated.

None of the RCTs in this review investigated frailty as the primary outcome. However, an emerging application of FRAIL-NH may be to monitor changes in frailty status over time as an outcome in RCTs and cohort studies. This highlights the dynamic state of frailty and assists with identifying risk factors influencing shifts in frailty transitions. Future studies are needed to explore whether targeted interventions can delay or reverse frailty transitions. Similarly, FRAIL-NH may be used to describe frailty status of RCT participants. This is important because frail older people are often under-represented in RCTs $(12,62)$. FRAIL-NH can facilitate by establishing frailty profiles and examining potential differences in characteristics between intervention versus control groups. Since poor health status among frail residents may also contribute to lower rates of follow-up, another potential use of FRAIL-NH is to model characteristics of residents who drop-out of prospective intervention studies.

Given that the FRAIL-NH scale is predictive of hospitalization, mortality, and other important clinical outcomes, it may be useful as a routine screening tool in NHs. According to the World Health Organization's guide on screening programs (69), FRAIL-NH fulfills the criteria for a clinically meaningful screening method to reduce the incidence and severity of a condition by early detection and treatment. Mass population screening of frailty may not be the most costeffective approach and requires further research to establish its feasibility and effectiveness at improving outcomes (66). However, frailty screening in adults $\geq 70$ years when accessing health care is recommended by major international frailty consensus groups across Europe, North America and AsiaPacific $(1,70,71)$.

The New Zealand Frailty Care Guides recommended the use of the FRAIL-NH scale to assess gradual deterioration in residents (72). Future studies should explore the potential integration of FRAIL-NH screening into routine care planning and whether this translates to improved outcomes for residents and NHs. The Australian National Aged Care Classification describes frailty as a factor driving $\mathrm{NH}$ resource use (73). Consideration of frailty status can assist clinicians and $\mathrm{NH}$ providers to identify residents at risk of harm, and implement strategies to prevent the onset and development of frailty. FRAIL-NH may have a potential role in identifying and accounting for care burden associated with frailty to better estimate funding and staff allocation.

\section{Conclusion}

In seven years, the FRAIL-NH scale has been applied in 20 countries and adapted into three languages. Despite being applied with a range of cut-offs, FRAIL-NH was associated with various factors indicative of higher care needs. FRAIL$\mathrm{NH}$ demonstrated good agreement and had similar predictive properties as other well-established but more complex frailty scales. FRAIL-NH was predictive of falls, cognitive or functional decline, hospitalization, and mortality across different settings. The association with adverse health outcomes highlights its value in guiding care for frail residents in NHs.

\section{Ethical standards: This study did not include any animal or human experiments.}

Funding sources: SJL, RV and JSB are supported by the National Health and Medical Research Council (NHMRC) Centre of Research Excellence in Frailty and Healthy Ageing. SJL is supported by the Australian Government Research Training Program Scholarship. SJL and LAD are supported by postgraduate research scholarships funded by Monash University. JSB is supported by a NHMRC Boosting Dementia Research Leadership Fellowship.

Conflicts of interest: RV was previously a board member of Resthaven Inc. and is currently on the clinical governance committee. In the recent past, she has received honoraria, speakers and educational grants in various combinations from Nutricia, Abbott and Nestlé. JSB has received research grants paid to his employer from NHMRC, Dementia Australia Research Foundation, Yulgilbar Foundation, Dementia Centre for Research Collaboration, Victorian Government Department of Health and Human Services, GlaxoSmithKline Independent Medical Education, Aged Care Quality and Safety Commission, and several aged care provider organizations. SJL, SL and LAD declare no conflicts of interest.

Acknowledgements: The authors gratefully acknowledge the assistance of Shota Hamada, Xiwen (Simon) Qin and JiaWen Poh with translation; and the preliminary background work by Monash University pharmacy students: Kenny Ong, Mohd Bin Mohamad Emla, Sakar Gurung, Tran Nguyen, and You Wong.

\section{References}

1. Morley JE, Vellas B, van Kan GA, Anker SD, Bauer JM, Bernabei R, Cesari M, Chumlea WC, Doehner W, Evans J, Fried LP, Guralnik JM, Katz PR, Malmstrom TK, McCarter RJ, Gutierrez Robledo LM, Rockwood K, von Haehling S, Vandewoude MF, Walston J. Frailty consensus: a call to action. J Am Med Dir Assoc. 2013;14(6):392-7. doi: 10.1016/j.jamda.2013.03.022.

2. Clegg A, Young J, Iliffe S, Rikkert MO, Rockwood K. Frailty in elderly people. Lancet. 2013;381(9868):752-62. doi: 10.1016/S0140-6736(12)62167-9.

3. Fan Y, Huang J, Zhou Y, Gu X, Gong D. Does the Impact of Frailty on All-Cause Mortality in Older Persons Differ between Women and Men? A Meta-Analysis. J Am Med Dir Assoc. 2021;22(3):606 e1- e6. doi: 10.1016/j.jamda.2020.05.059.

4. Fan L, Tian Y, Wang J, Ding Y, Wang S, Xue H, Du W. Frailty Predicts Increased Health Care Utilization Among Community-Dwelling Older Adults: A Longitudinal Study in China. J Am Med Dir Assoc. 2021. doi: 10.1016/j.jamda.2021.01.082.

5. Zhang X, Dou Q, Zhang W, Wang C, Xie X, Yang Y, Zeng Y. Frailty as a Predictor of All-Cause Mortality Among Older Nursing Home Residents: A Systematic Review and Meta-analysis. J Am Med Dir Assoc. 2019;20(6):657-63 e4. doi: 10.1016/j. jamda.2018.11.018

6. Vermeiren S, Vella-Azzopardi R, Beckwee D, Habbig AK, Scafoglieri A, Jansen B, Bautmans I, Gerontopole Brussels Study g. Frailty and the Prediction of Negative Health Outcomes: A Meta-Analysis. J Am Med Dir Assoc. 2016;17(12):1163 e1- e17. doi: 10.1016/j.jamda.2016.09.010.

7. Collard RM, Boter H, Schoevers RA, Oude Voshaar RC. Prevalence of frailty in community-dwelling older persons: a systematic review. J Am Geriatr Soc 2012;60(8):1487-92. doi: 10.1111/j.1532-5415.2012.04054.x.

8. Kojima G. Prevalence of Frailty in Nursing Homes: A Systematic Review and MetaAnalysis. J Am Med Dir Assoc. 2015;16(11):940-5. doi: 10.1016/j.jamda.2015.06.025.

9. Rolland Y, Tolson D, Morley JE, Vellas B. The International Association of Gerontology and Geriatrics (IAGG) nursing home initiative. J Am Med Dir Assoc. 2014;15(5):307-8. doi: 10.1016/j.jamda.2014.03.002.

10. Muth C, Blom JW, Smith SM, Johnell K, Gonzalez-Gonzalez AI, Nguyen TS, Brueckle MS, Cesari M, Tinetti ME, Valderas JM. Evidence supporting the best clinical management of patients with multimorbidity and polypharmacy: a systematic guideline review and expert consensus. J Intern Med. 2019;285(3):272-88. doi: 10.1111/joim.12842.

11. Boyd C, Smith CD, Masoudi FA, Blaum CS, Dodson JA, Green AR, Kelley A, Matlock D, Ouellet J, Rich MW, Schoenborn NL, Tinetti ME. Decision Making for Older Adults With Multiple Chronic Conditions: Executive Summary for the American Geriatrics Society Guiding Principles on the Care of Older Adults With Multimorbidity. J Am Geriatr Soc. 2019;67(4):665-73. doi: 10.1111/jgs.15809.

12. Onder G, Vetrano DL, Marengoni A, Bell JS, Johnell K, Palmer K, Optimising Pharmacotherapy through Pharmacoepidemiology Network. Accounting for frailty 
when treating chronic diseases. Eur J Intern Med. 2018;56:49-52. doi: 10.1016/j. ejim.2018.02.021.

13. Allers K, Hoffmann F, Schnakenberg R. Hospitalizations of nursing home residents at the end of life: A systematic review. Palliat Med. 2019;33(10):1282-98. doi: 10.1177/0269216319866648.

14. Faller JW, Pereira DDN, de Souza S, Nampo FK, Orlandi FS, Matumoto S Instruments for the detection of frailty syndrome in older adults: A systematic review. PLoS One. 2019;14(4):e0216166. doi: 10.1371/journal.pone.0216166.

15. Fried LP, Tangen CM, Walston J, Newman AB, Hirsch C, Gottdiener J, Seeman T, Tracy R, Kop WJ, Burke G, McBurnie MA, Cardiovascular Health Study Collaborative Research G. Frailty in older adults: evidence for a phenotype. J Gerontol A Biol Sci Med Sci. 2001;56(3):M146-56. doi: 10.1093/gerona/56.3.m146.

16. Mitnitski AB, Mogilner AJ, Rockwood K. Accumulation of deficits as a proxy measure of aging. Sci World J. 2001;1:323-36. doi: 10.1100/tsw.2001.58.

17. Kaehr E, Visvanathan R, Malmstrom TK, Morley JE. Frailty in nursing homes: the FRAIL-NH Scale. J Am Med Dir Assoc. 2015;16(2):87-9. doi: 10.1016/j. jamda.2014.12.002.

18. Page MJ, McKenzie JE, Bossuyt PM, Boutron I, Hoffmann TC, Mulrow CD, Shamseer L, Tetzlaff JM, Akl EA, Brennan SE, Chou R, Glanville J, Grimshaw JM, Hrobjartsson A, Lalu MM, Li T, Loder EW, Mayo-Wilson E, McDonald S, McGuinness LA, Stewart LA, Thomas J, Tricco AC, Welch VA, Whiting P, Moher D. The PRISMA 2020 statement: an updated guideline for reporting systematic reviews. BMJ. 2021;372:n71. doi: 10.1136/bmj.n71.

19. Liau SJ, Dowd LA, Lalic S, Visvanathan R, Bell JS (2020) The FRAIL-NH scale: Systematic review of the use, validity and cross-cultural adaptations for frailty screening in nursing homes. PROSPERO: International prospective register of systematic reviews. https://www.crd.york.ac.uk/prospero/display_record. php?ID=CRD42020185159. Accessed 13 September 2020.

20. Moola S, Munn Z, Tufanaru C, Aromataris E, Sears K, Sfetcu R, Currie M, Qureshi R, Mattis P, Lisy K, Mu P-F (2017) Chapter 7: Systematic reviews of etiology and risk. Joanna Briggs Institute Reviewer's Manual. The Joanna Briggs Institute. https://jbi. global/critical-appraisal-tools. Accessed 5 June 2020.

21. Archibald M, Lawless M, Ambagtsheer RC, Kitson A. Older adults' understandings and perspectives on frailty in community and residential aged care: an interpretive description. BMJ Open. 2020;10(3):e035339. doi: 10.1136/bmjopen-2019-035339.

22. Chen EY, Bell JS, Ilomaki J, Keen C, Corlis M, Hogan M, Van Emden J, Hilmer SN, Sluggett JK. Medication Regimen Complexity In 8 Australian Residential Aged Care Facilities: Impact Of Age, Length Of Stay, Comorbidity, Frailty, And Dependence In Activities Of Daily Living. Clin Interv Aging. 2019;14:1783-95. doi: 10.2147/CIA S216705.

23. Hendrix I, Page AT, Korhonen MJ, Bell JS, Tan ECK, Visvanathan R, Cooper T, Robson L, Sluggett JK. Patterns of High-Dose and Long-Term Proton Pump Inhibitor Use: A Cross-Sectional Study in Six South Australian Residential Aged Care Services. Drugs Real World Outcomes. 2019;6(3):105-13. doi: 10.1007/s40801-019-0157-1.

24. Jadczak AD, Robson L, Cooper T, Bell JS, Visvanathan R, Collaborators FS. The Frailty In Residential Sector over Time (FIRST) study: methods and baseline cohort description. BMC Geriatr. 2021;21(1):99. doi: 10.1186/s12877-020-01974-1.

25. Kerry M, Bell JS, Keen C, Sluggett JK, Ilomaki J, Jokanovic N, Cooper T, Robson L, Tan ECK. Multiple antihypertensive use and risk of mortality in residents of aged care services: a prospective cohort study. Aging Clin Exp Res. 2020;32(8):1541-9. doi: 10.1007/s40520-019-01336-x.

26. Korhonen MJ, Ilomaki J, Sluggett JK, Brookhart MA, Visvanathan R, Cooper T, Robson L, Bell JS. Selective prescribing of statins and the risk of mortality, hospitalizations, and falls in aged care services. J Clin Lipidol. 2018;12(3):652-61. doi: 10.1016/j.jacl.2018.02.012.

27. Sluggett JK, Chen EYH, Ilomaki J, Corlis M, Van Emden J, Hogan M, Caporale T, Keen C, Hopkins R, Ooi CE, Hilmer SN, Hughes GA, Luu A, Nguyen KH, Comans T, Edwards S, Quirke L, Patching A, Bell JS. Reducing the Burden of Complex Medication Regimens: SImplification of Medications Prescribed to Long-tErm care Residents (SIMPLER) Cluster Randomized Controlled Trial. J Am Med Dir Assoc. 2020;21(8):1114-20 e4. doi: 10.1016/j.jamda.2020.02.003

28. Sluggett JK, Hopkins RE, Chen EY, Ilomaki J, Corlis M, Van Emden J, Hogan M, Caporale T, Ooi CE, Hilmer SN, Bell JS. Impact of Medication Regimen Simplification on Medication Administration Times and Health Outcomes in Residential Aged Care: 12 Month Follow Up of the SIMPLER Randomized Controlled Trial. J Clin Med. 2020;9(4):1053. doi: 10.3390/jcm9041053.

29. Theou O, Tan EC, Bell JS, Emery T, Robson L, Morley JE, Rockwood K, Visvanathan R. Frailty Levels in Residential Aged Care Facilities Measured Using the Frailty Index and FRAIL-NH Scale. J Am Geriatr Soc. 2016;64(11):e207-e12. doi: 10.1111/ jgs. 14490 .

30. Theou O, Sluggett JK, Bell JS, Lalic S, Cooper T, Robson L, Morley JE, Rockwood K, Visvanathan R. Frailty, Hospitalization, and Mortality in Residential Aged Care. J Gerontol A Biol Sci Med Sci. 2018;73(8):1090-6. doi: 10.1093/gerona/glx185.

31. Wang KN, Bell JS, Gilmartin-Thomas JFM, Tan ECK, Cooper T, Robson L, Ilomaki J. Use of Falls Risk Increasing Drugs in Residents at High and Low Falls Risk in Aged Care Services. J Appl Gerontol. 2021;40(1):77-86. doi: 10.1177/0733464819888848.

32. Dugré N, Bell JS, Hopkins RE, Ilomäki J, Chen EYH, Corlis M, Van Emden J,
Hogan M, Sluggett JK. Impact of Medication Regimen Simplification on Medication Incidents in Residential Aged Care: SIMPLER Randomized Controlled Trial. J Clin Med. 2021;10(5):1104. doi: 10.3390/jcm10051104.

33. Sharma M, Wong XY, Bell JS, Corlis M, Hogan M, Sluggett JK. Trajectories of pro re nata (PRN) medication prescribing and administration in long-term care facilities. Res Social Adm Pharm. 2021;17(8):1463-8. doi: 10.1016/j.sapharm.2020.11.003.

34. Archibald MM, Lawless MT, Ambagtsheer RC, Kitson AL. Understanding consumer perceptions of frailty screening to inform knowledge translation and health service improvements. Age Ageing. 2021;50(1):227-32. doi: 10.1093/ageing/afaa187.

35. Ge F, Liu M, Tang S, Lu Y, Szanton SL. Assessing Frailty in Chinese Nursing Home Older Adults: A Comparison between the Frail-NH Scale and Frailty Index. J Nutr Health Aging. 2019;23(3):291-8. doi: 10.1007/s12603-019-1156-3.

36. Ge F, Liu M, Lu Y, Tang S. Comparison of frail status with FRAIL-NH Scale and Tilburg Frailty Indicator among institutional older adults. Chinese Nursing Management. 2019;19(4):513-7. doi: 10.3969/j.issn.1672-1756.2019.04.008.

37. Ge F, Liu W, Liu M, Tang S, Lu Y, Hou T. Accessing the discriminatory performance of FRAIL-NH in two-class and three-class frailty and examining its agreement with the frailty index among nursing home residents in mainland China. BMC Geriatr 2019;19(1):296. doi: 10.1186/s12877-019-1314-9.

38. Si H, Jin Y, Qiao X, Tian X, Liu X, Wang C. Comparing Diagnostic Properties of the FRAIL-NH Scale and 4 Frailty Screening Instruments among Chinese Institutionalized Older Adults. J Nutr Health Aging. 2020;24(2):188-93. doi: 10.1007/s12603-0191301-z.

39. Yang M, Zhuo Y, Hu X, Xie L. Predictive validity of two frailty tools for mortality in Chinese nursing home residents: frailty index based on common laboratory test (FI-Lab) versus FRAIL-NH. Aging Clin Exp Res. 2018;30(12):1445-52. doi: 10.1007/ s40520-018-1041-7.

40. Zhao M, Mou H, Zhu S, Li M, Wang K. Cross-cultural adaptation and validation of the FRAIL-NH scale for Chinese nursing home residents: A methodological and cross-sectional study. Int J Nurs Stud. 2020;105:103556. doi: 10.1016/j. ijnurstu.2020.103556.

41. Contreras-Escámez B, Izquierdo M, Galbete Jiménez A, Gutiérrez-Valencia M, Cedeno-Veloz BA, Martínez-Velilla N. Diferencias en la capacidad predictiva para declive funcional, cognitivo y mortalidad para distintas escalas de fragilidad: un estudio de cohortes longitudinal. Med Clin (Barc). 2020;155:18-22. doi: 10.1016/j. medcle.2020.01.008.

42. Gutierrez-Valencia M, Izquierdo M, Lacalle-Fabo E, Marin-Epelde I, RamonEspinoza MF, Domene-Domene T, Casas-Herrero A, Galbete A, Martinez-Velilla N Relationship between frailty, polypharmacy, and underprescription in older adults living in nursing homes. Eur J Clin Pharmacol. 2018;74(7):961-70. doi: 10.1007/ s00228-018-2452-2.

43. Martinez-Velilla N, Herce PA, Herrero AC, Gutierrez-Valencia M, Saez de Asteasu ML, Mateos AS, Zubillaga AC, Beroiz BI, Jimenez AG, Izquierdo M. Heterogeneity of Different Tools for Detecting the Prevalence of Frailty in Nursing Homes: Feasibility and Meaning of Different Approaches. J Am Med Dir Assoc. 2017;18(10):898 e1- e8. doi: 10.1016/j.jamda.2017.06.016.

44. Kaehr EW, Pape LC, Malmstrom TK, Morley JE. FRAIL-NH Predicts Outcomes in Long Term Care. J Nutr Health Aging. 2016;20(2):192-8. doi: 10.1007/s12603-0160682-5.

45. Yuan Y, Lapane KL, Tjia J, Baek J, Liu SH, Ulbricht CM. Physical Frailty and Cognitive Impairment in Older Adults in United States Nursing Homes. Dement Geriatr Cogn Disord. 2021;50(1):60-7. doi: 10.1159/000515140.

46. Little MO, Sanford AM, Malmstrom TK, Traber C, Morley JE. Incorporation of Medicare Annual Wellness Visits into the Routine Clinical Care of Nursing Home Residents. J Am Geriatr Soc. 2021;69(4):1100-2. doi: 10.1111/jgs.16984.

47. Vasconcellos Romanini C, Vilas Boas P, Cecato JF, Robello E, Borges MK, Martinelli JE, Aprahamian I. Prediction of Death with the FRAIL-NH in Institutionalized Older Adults: A Longitudinal Study from a Middle-Income Country. J Nutr Health Aging. 2020;24(8):817-20. doi: 10.1007/s12603-020-1464-7.

48. de Barros ENC, Valle APD, Braga PE, Viscondi JYK, Fonseca A, Vanni T, Silva AD, Cardoso MR, Villas-Boas PJF, Precioso AR. COVID-19 in long-term care facilities in Brazil: serological survey in a post-outbreak setting. Rev Inst Med Trop Sao Paulo. 2021;63:e10. doi: 10.1590/s1678-9946202163010.

49. [Development of FRAIL-NH scale Japanese version]. [Nihon Ronen Igakkai Zasshi]. Japanese Journal of Geriatrics. 2021;58(1):164-6. [in Japanese]. doi: 10.3143/ geriatrics.58.164

50. Papadopoulos C, Castro N, Nigath A, Davidson R, Faulkes N, Menicatti R, Khaliq AA, Recchiuto C, Battistuzzi L, Randhawa G, Merton L, Kanoria S, Chong NY, Kamide H, Hewson D, Sgorbissa A. The CARESSES Randomised Controlled Trial Exploring the Health-Related Impact of Culturally Competent Artificial Intelligence Embedded Into Socially Assistive Robots and Tested in Older Adult Care Homes. Int J Soc Robot. 2021:1-12. doi: 10.1007/s12369-021-00781-x.

51. Ho V, Chen C, Ho S, Hooi B, Chin LS, Merchant RA. Healthcare utilisation in the last year of life in internal medicine, young-old versus old-old. BMC Geriatr. 2020;20(1):495. doi: 10.1186/s12877-020-01894-0.

52. Chong E, Huang Y, Chan M, Tan HN, Lim WS. Concurrent and Predictive Validity of FRAIL-NH in Hospitalized Older Persons: An Exploratory Study. J Am Med Dir 
Assoc. 2021. doi: 10.1016/j.jamda.2021.04.017.

53. Buckinx F, Croisier JL, Reginster JY, Lenaerts C, Brunois T, Rygaert X, Petermans J, Bruyere O. Prediction of the Incidence of Falls and Deaths Among Elderly Nursing Home Residents: The SENIOR Study. J Am Med Dir Assoc. 2018;19(1):18-24. doi: 10.1016/j.jamda.2017.06.014.

54. Chu CH, Biss RK, Cooper L, Quan AML, Matulis H. Exergaming Platform for Older Adults Residing in Long-Term Care Homes: User-Centered Design, Development, and Usability Study. JMIR Serious Games. 2021;9(1):e22370. doi: 10.2196/22370.

55. Villani ER, Vetrano DL, Liperoti R, Palmer K, Denkinger M, van der Roest HG, Bernabei R, Onder G. Relationship between frailty and drug use among nursing homes residents: results from the SHELTER study. Aging Clin Exp Res. 2021 [Published online ahead of print]. doi: 10.1007/s40520-021-01797-z.

56. De Silva TR, Theou O, Vellas B, Cesari M, Visvanathan R. Frailty Screening (FRAIL-NH) and Mortality in French Nursing Homes: Results From the Incidence of Pneumonia and Related Consequences in Nursing Home Residents Study. J Am Med Dir Assoc. 2018;19(5):411-4. doi: 10.1016/j.jamda.2017.12.101.

57. Luo H, Lum TY, Wong GH, Kwan JS, Tang JY, Chi I. Predicting Adverse Health Outcomes in Nursing Homes: A 9-Year Longitudinal Study and Development of the FRAIL-Minimum Data Set (MDS) Quick Screening Tool. J Am Med Dir Assoc. 2015;16(12):1042-7. doi: 10.1016/j.jamda.2015.09.006.

58. Greco GI, Noale M, Trevisan C, Zatti G, Dalla Pozza M, Lazzarin M, Haxhia L, Ramon R, Imoscopi A, Bellon S, Maggi S, Sergi G. Increase in Frailty in Nursing Home Survivors of Coronavirus Disease 2019: Comparison With Noninfected Residents. J Am Med Dir Assoc. 2021;22(5):943-7 e3. doi: 10.1016/j. jamda.2021.02.019.

59. Ga H, Won CW, Jung HW. Use of the Frailty Index and FRAIL-NH Scale for the Assessment of the Frailty Status of Elderly Individuals Admitted in a Long-term Care Hospital in Korea. Ann Geriatr Med Res. 2018;22(1):20-5. doi: 10.4235/ agmr.2018.22.1.20.

60. Peng TC, Chen WL, Wu LW, Chang YW, Kao TW. The Prevalence of Frailty by the FRAIL-NH Scale in Taiwan Nursing Home Residents. J Nutr Health Aging. 2020;24(5):507-11. doi: 10.1007/s12603-020-1350-3.

61. Hoover M, Rotermann M, Sanmartin C, Bernier J. Validation of an index to estimate the prevalence of frailty among community-dwelling seniors. Health Rep. 2013;24(9):10-7.

62. Liau SJ, Lalic S, Sluggett JK, Cesari M, Onder G, Vetrano DL, Morin L, Hartikainen S, Hamina A, Johnell K, Tan ECK, Visvanathan R, Bell JS, Optimizing Geriatric Pharmacotherapy through Pharmacoepidemiology Network (OPPEN). Medication Management in Frail Older People: Consensus Principles for Clinical Practice, Research, and Education. J Am Med Dir Assoc. 2021;22(1):43-9. doi: 10.1016/j. jamda.2020.05.004

63. Wimmer BC, Cross AJ, Jokanovic N, Wiese MD, George J, Johnell K, Diug B, Bell JS. Clinical Outcomes Associated with Medication Regimen Complexity in Older People: A Systematic Review. J Am Geriatr Soc. 2017;65(4):747-53. doi: 10.1111/ jgs.14682.
64. Lalic S, Sluggett JK, Ilomaki J, Wimmer BC, Tan EC, Robson L, Emery T, Bell JS. Polypharmacy and Medication Regimen Complexity as Risk Factors for Hospitalization Among Residents of Long-Term Care Facilities: A Prospective Cohort Study. J Am Med Dir Assoc. 2016;17(11):1067 e1- e6. doi: 10.1016/j. jamda.2016.08.019.

65. Bell JS, McInerney B, Chen EY, Bergen PJ, Reynolds L, Sluggett JK. Strategies to simplify complex medication regimens. Aust J Gen Pract. 2021;50(1-2):43-8. doi 10.31128/AJGP-04-20-5322.

66. Turner G, Clegg A, British Geriatrics Society, Age U. K., Royal College of General Practitioners. Best practice guidelines for the management of frailty: a British Geriatrics Society, Age UK and Royal College of General Practitioners report. Age Ageing. 2014;43(6):744-7. doi: 10.1093/ageing/afu138.

67. Satake S, Kinoshita K, Shimizu M, Arahata Y, Arai H. Prediction of nursing home admission by the FRAIL-NH in the post-acute care setting. Eur Geriatr Med 2019;10(Suppl 1):S253-4. doi: 10.1007/s41999-019-00221-0.

68. Mariscal BE, Mena-Madrazo JA. Use of the Spanish Version of the Frail-NH Scale to Predict Adverse Outomes in a Nursing Home in Mexico City. J Am Med Dir Assoc. 2018;19(3):B31-B. doi: 10.1016/j.jamda.2017.12.094.

69. World Health Organization Regional Office for Europe (2020) Screening programmes: a short guide. Increase effectiveness, maximize benefits and minimize harm. World Health Organization. https://apps.who.int/iris/handle/10665/330829. Accessed 9 June 2021.

70. ADVANTAGE Joint Action (2019) Managing Frailty. A comprehensive approach to promote disability-free advanced age in Europe: the ADVANTAGE initiative. Final Layman Report. https://www.advantageja.eu/images/Layman_report_final.pdf Accessed 9 June 2021.

71. Dent E, Lien C, Lim WS, Wong WC, Wong CH, Ng TP, Woo J, Dong B, de la Vega S, Hua Poi PJ, Kamaruzzaman SBB, Won C, Chen LK, Rockwood K, Arai H, RodriguezManas L, Cao L, Cesari M, Chan P, Leung E, Landi F, Fried LP, Morley JE, Vellas B, Flicker L. The Asia-Pacific Clinical Practice Guidelines for the Management of Frailty. J Am Med Dir Assoc. 2017;18(7):564-75. doi: 10.1016/j.jamda.2017.04.018.

72. Health Quality \& Safety Commission New Zealand (2019) Frailty care guides I Ngã aratohu maimoa hauwarea. https://www.hqsc.govt.nz/assets/ARC/PR/Frailty_care_ guides/Frailty-care-guide-master-update-Feb-2021.pdf. Accessed 10 June 2021.

73. Eagar K, Gordon R, Snoek MF, Loggie C, Westera A, Samsa PD, Kobel C. The Australian National Aged Care Classification (AN-ACC): a new casemix classification for residential aged care. Med J Aust. 2020;213(8):359-63. doi: 10.5694/mja2.50703.

How to cite this article: S.J. Liau, S. Lalic, R. Visvanathan, et al. The FRAIL-NH Scale: Systematic Review of the Use, Validity and Adaptations for Frailty Screening in Nursing Homes. J Nutr Health Aging. 2021;25(10):1205-1216, http://dx.doi.org/10.1007/ s12603-021-1694-3 